\title{
Diagnóstico imuno-histoquímico e caracterização anatomopatológica de clamidiose em psitacídeos ${ }^{1}$
}

\author{
Renata A. Casagrande ${ }^{2,3}$, Veronica R. Machado², Suyene O. de Souza ${ }^{2}$, Tatiane T.N. \\ Watanabe $^{2}$, Luciana Sonne ${ }^{2}$, Saulo P. Pavarini ${ }^{2}$ e David Driemeier ${ }^{2 *}$
}

\begin{abstract}
Casagrande R.A., Machado V.R., Souza S.O., Watanabe T.T.N., Sonne L., Pavarini S.P. \& Driemeier D. 2014. [Immunohistochemical diagnosis and pathological characterization of chlamydiosis in psittacine.] Diagnóstico imuno-histoquímico e caracterização anatomopatológica de clamidiose em psitacídeos. Pesquisa Veterinária Brasileira 34(9):885-890. Setor de Patologia Veterinária, Faculdade de Veterinária, Universidade Federal do Rio Grande do Sul, Av. Bento Gonçalves 9090, Porto Alegre, RS 91540-000, Brazil. E-mail: davetpat@ufrgs.br

Chlamydiosis is caused by Chlamydophila psittaci and is one of the most important avian zoonosis. A retrospective study in psittacines was performed from 1995 to 2012 with immunohistochemistry (IHC) anti-Chlamydia. Hundred eleven cases were evaluated and twelve birds died due to chlamydiosis. The birds were obtained from illegal commerce traffic or captive conditions (zoos, breeding birds, wildlife rehabilitation center and pets). Grossly, there were hepatomegaly (4/12) with yellowish-white areas $(3 / 12)$, splenomegaly $(2 / 12)$, splenic rupture $(1 / 12)$, fibrin deposition in pericardial sac $(1 / 12)$, fibrinous polyserositis $(1 / 12)$, and in three cases lesion was not found. Histopathological evaluation revealed mononuclear necrotizing hepatitis $(7 / 12)$, mononuclear hepatitis $(3 / 12)$, biliary duct hyperplasia (8/12), histiocytic necrotizing splenitis $(9 / 12)$, hemosiderosis in liver $(9 / 12)$ and spleen $(9 / 12)$, mononuclear aerosaculitis $(4 / 12)$, fibrin heterophilic pericarditis (2/12), lymphoid necrosis $(1 / 12)$ and depletion of bursa Fabricius (1/12), fibrinous pneumonia (1/12), mononuclear nephritis (1/12), and renal granulomas (1/12). Basophilic intracytoplasmic inclusions (elementary bodies) were observed in liver (2/12), spleen and kidney (1/12). Positive immunostaining for Chlamydia could be detected in liver (11/12), spleen (7/9), lung (3/9), kidney (2/8), intestines $(2 / 3)$, air sacs $(1 / 4)$ and bursa of Fabricius (1/2). It was concluded that IHC can be used as postmortem definitive diagnosis of chlamydiosis in psittacines.
\end{abstract}

INDEX TERMS: Zoonosis, bird, pathology, immunohistochemistry, ornithosis, Chlamydophila psittaci.

RESUMO.- A clamidiose é causada por Chlamydophila psittaci e representa uma das principais zoonoses de origem aviária. Realizou-se um estudo retrospectivo em psitacídeos do período de 1995 a 2012 e exame imuno-histoquímico (IHQ) anti-Chlamydia. Foram avaliados 111 casos, dos quais 12 foram a óbito devido à clamidiose. As aves eram provenientes de apreensão ou cativeiro (zoológicos, criatórios,

\footnotetext{
${ }^{1}$ Recebido em 17 de abril de 2014.

Aceito para publicação em 4 de setembro de 2014.

${ }^{2}$ Departamento de Patologia Clínica Veterinária, Faculdade de Veterinária, Universidade Federal do Rio Grande do Sul (UFRGS), Av. Bento Gonçalves 9090, Porto Alegre, RS 95320-000, Brasil. *Autor para correspondência: davetpat@ufrgs.br

${ }^{3}$ Instituto Federal Catarinense, SC-283 Km 8, Vila Fragosos, Concórdia, SC 89700-000, Brasil.
}

centros de triagem e domicílios). À necropsia observou-se fígado aumentado (4/12) com áreas branco-amareladas $(3 / 12)$, baço aumentado $(2 / 12)$ e rompido $(1 / 12)$, saco pericárdico com deposição de fibrina (1/12), polisserosite fibrinosa (1/12) e em três casos não havia lesões. $\mathrm{Na}$ avaliação histopatológica evidenciou-se hepatite necrótica mononuclear $(7 / 12)$, hepatite mononuclear $(3 / 12)$, hiperplasia de ductos biliares (8/12), esplenite necrótica histiocitária (9/12), hemossiderose em fígado $(9 / 12)$ e baço $(9 / 12)$, aerossaculite mononuclear $(4 / 12)$, pericardite fibrino-heterofílica $(2 / 12)$, necrose $(1 / 12)$ e rarefação (1/12) linfoide de bursa de Fabricius, pneumonia fibrinosa $(1 / 12)$, nefrite mononuclear $(1 / 12)$ e granulomas renais (1/12). Observaram-se inclusões basofílicas intracitoplasmáticas (corpos elementares) em fígado $(2 / 12)$, baço e 
rins (1/12). Evidenciou-se imunomarcação anti-Chlamydia em fígado $(11 / 12)$, baço $(7 / 9)$, pulmões $(3 / 9)$, rins $(2 / 8)$, intestinos (2/3), sacos aéreos (1/4) e bursa de Fabricius (1/2). A IHQ poderá ser utilizada como forma de diagnóstico definitivo post mortem de clamidiose em psitacídeos no Brasil.

TERMOS DE INDEXAÇÃO: Zoonose, ave, patologia, imuno-histoquímica, clamidiose, Chlamydophila psittaci.

\section{INTRODUÇÃO}

A clamidiose, uma doença infecciosa de aves e mamíferos, é causada pela bactéria intracelular obrigatória Chlamydophila psittaci (C. psittaci). Esse agente já foi detectado em mais de 460 espécies de aves e os psitacídeos são os mais acometidos (Kaleta \& Taday 2003). Em humanos C. psittaci causa a clamidiose, uma das principais zoonoses de origem aviária (Heddema et al. 2006, Vanrompay et al. 2007, Petrovay \& Balla 2008, Harkinezhad et al. 2009, Raso et al. 2010).

As aves podem desenvolver uma forma aguda, subaguda, crônica e inaparente (subclínica) da doença, dependendo do estado imunológico e da patogenicidade da bactéria (Andersen \& Vanrompay 2008). Os sinais clínicos são inespecíficos e incluem anorexia, depressão, penas eriçadas, conjuntivite, sinusite, rinite, dispneia, diarreia, poliúria, tremores e convulsões (Gerlach 1994, Andersen \& Vanrompay 2008). A forma mais comum é a subclínica, na qual as aves são portadoras e a eliminação do agente é intermitente (Proença et al. 2011).

No Brasil os relatos de clamidiose em aves são escassos. Um surto foi descrito em 58 papagaios apreendidos do tráfico com mortalidade de 96,5\% (Raso et al. 2004) e outro em 15 psitacídeos em um Centro de Triagem de Animais Silvestres (Ecco et al. 2009). Em um estudo a detecção de $C$. psittaci em psitacídeos de cativeiro, aparentemente saudáveis, variou de 16,7 a 56,1\% (Raso et al. 2002) e em psitacídeos de vida livre de 6,3 a 26,7\% (Raso et al. 2006). Além das aves selvagens, essa enfermidade também é considerada bastante importante em aves de produção, podendo causar graves problemas respiratórios e alta mortalidade, principalmente em criações de perus (Van Loock et al. 2006).

A clamidiose possui prevalência subestimada devido à ausência de sinais clínicos patognomônicos, pela dificuldade de se ter um diagnóstico definitivo e pela ausência de testes comerciais padronizados (Proença et al. 2011). No entanto, um diagnóstico rápido e acurado é necessário, devido à alta mortalidade que pode ocorrer nas aves (Raso et al. 2004) e ao seu potencial zoonótico (Longbottom \& Coulter 2003). Dentre os diferentes métodos de diagnóstico, a imuno-histoquímica (IHQ) é considerada o método post mortem mais acurado para tecidos fixados em formol (Elder \& Brown 1999, Ecco et al. 2009).

0 objetivo deste trabalho foi descrever, através de um estudo retrospectivo, as características anatomopatológicas e imuno-histoquímicas de casos suspeitos de clamidiose em psitacídeos enviados ao Setor de Patologia Veterinária (SPV) da Universidade Federal do Rio Grande do Sul (UFRGS), no período de 1995 a 2012.

\section{MATERIAL E MÉTODOS}

Os arquivos de necropsia e exame histopatológico de psitacídeos foram levantados e revisados do período de 1995 a 2012 do SPV-UFRGS. Dados referentes às aves foram registrados, agrupados e analisados. Realizou-se a busca dos blocos de parafina e posteriormente os cortes e coloração pelo método de hematoxilina e eosina (H\&E) para caracterização histológica das lesões.

Nos casos em que havia amostra de fígado, os fragmentos de todos os órgãos foram submetidos à técnica de IHQ pelo método estreptavidina-biotina ligada à peroxidase. 0 bloqueio da atividade da peroxidase endógena foi realizado com a incubação dos cortes dos tecidos em solução a $10 \%$ de peróxido de hidrogênio (30 vol.) em metanol. Para a recuperação antigênica utilizou-se proteinase K (DakoCytomation) em temperatura ambiente por sete minutos. $\mathrm{O}$ anticorpo monoclonal anti-Chlamydia (clone ACI, 10R-C124A, Fitzgerald) foi diluído em 1:100 em solução salina tamponada com fosfato (PBS). As lâminas foram incubadas em câmara úmida por 14-16 horas (overnight) a $4^{\circ} \mathrm{C}$ como o anticorpo primário e, após esta etapa, os cortes foram incubados com anticorpo secundário biotinilado ligado a estreptavidina-peroxidase (kit LSAB-HRP, K0690, DakoCytomation). 0 cromógeno utilizado para a revelação foi o 3-amino-9-etilcarbazol (AEC, K3469, DakoCytomation) e foi utilizada hematoxilina de Mayer na contracoloração, seguida de montagem em meio aquoso (S1964, DakoCytomation). Como controle positivo utilizou-se um corte histológico de fígado de um psitacídeo com marcação IHQ positiva para Chlamydia proveniente da Universidade da Georgia, Estados Unidos (UGA, USA).

As diferentes intensidades de marcação foram indicadas da seguinte forma: (-) ausência de marcação, (+) marcação discreta, $(++)$ marcação moderada e $(+++)$ marcação acentuada.

\section{RESULTADOS}

No período de 1995 a 2012, foram realizados 128 diagnósticos histopatológicos de amostras de psitacídeos, em 111 casos realizou-se IHQ anti-Chlamydia e em 16 houve marcação. As características e manifestações clínicas desses psitacídeos encontram-se no Quadro 1. Todas as aves positivas para a IHQ anti-Chlamydia eram provenientes do estado do Rio Grande do Sul.

Quanto à origem, seis aves (casos 4 a 9) eram de uma apreensão de aproximadamente 450 caturritas (Myiopsitta monachus) efetuada pela Polícia Ambiental do Rio Grande do Sul (Surto 1). Após a apreensão as aves foram encaminhadas para zoológicos, hospitais e clínicas veterinárias e nesses locais várias pessoas auxiliaram no cuidado das aves, pois muitas eram filhotes e não se alimentavam sozinhas. Alguns dias após, aproximadamente 25 pessoas apresentaram náuseas, dores de cabeça e no corpo, febre e tiveram diagnóstico de psitacose. Algumas caturritas apresentavam sinais clínicos inespecíficos (Quadro 1), no entanto, a maioria estava aparentemente saudável. Todas as aves foram submetidas à eutanásia, 14 foram enviadas para necropsia, e dessas seis foram positivas na IHQ.

0 segundo surto foi diagnosticado em um zoológico, no qual três psitacídeos morreram em uma semana (casos 11, 12 e 13). Os outros seis casos $(1-3,10,14$ e 15) ocorreram de forma isolada e as aves eram provenientes de centros de triagem e cativeiros domiciliares (Quadro 1). 0 caso 16 era proveniente de um criatório de calopsitas (Nymphicus hollandicus) com plantel de 50 casais. Nos últimos meses havia morrido aproximadamente 50 filhotes de 15 a 90 
Quadro 1. Caracterização e manifestações clínicas dos psitacídeos acometidos por clamidiose

\begin{tabular}{|c|c|c|c|c|c|}
\hline Caso & Ano & Origem & Espécie & Idade & Manifestações clínicas \\
\hline 1 & 2007 & $\begin{array}{l}\text { Centro de } \\
\text { triagem }\end{array}$ & $\begin{array}{c}\text { Caturrita } \\
\text { (Myiopsitta monachus) }\end{array}$ & $\mathrm{NI}$ & $\mathrm{NI}$ \\
\hline 2 & 2007 & $\begin{array}{l}\text { Centro de } \\
\text { triagem }\end{array}$ & $\begin{array}{c}\text { Papagaio } \\
\text { (Amazona sp.) }\end{array}$ & $\mathrm{NI}$ & $\mathrm{NI}$ \\
\hline 3 & 2007 & Domiciliar & $\begin{array}{l}\text { Arara-canindé } \\
\text { (Ara ararauna) }\end{array}$ & 35 anos & $\begin{array}{l}\text { Encontrado } \\
\text { morto }\end{array}$ \\
\hline $4^{1}$ & 2007 & Apreensão & Caturrita & Filhote & Prostração, hiporexia \\
\hline $5^{1}$ & 2007 & Apreensão & Caturrita & Filhote & Prostração,hiporexia \\
\hline $6^{1}$ & 2007 & Apreensão & Caturrita & Filhote & Prostração, hiporexia \\
\hline $7^{1}$ & 2007 & Apreensão & Caturrita & Filhote & Prostração, hiporexia \\
\hline $8^{1}$ & 2007 & Apreensão & Caturrita & Filhote & Prostração, hiporexia \\
\hline $9^{1}$ & 2007 & Apreensão & Caturrita & Filhote & Prostração, hiporexia \\
\hline 10 & 2008 & Domiciliar & Calopsita & 2 meses & Encontrado morto \\
\hline \multicolumn{6}{|c|}{ (Nymphicus hollandicus) } \\
\hline $11^{\text {II }}$ & 2009 & Zoológico & $\begin{array}{l}\text { Papagaio-do-mangue } \\
\text { (Amazona amazonica) }\end{array}$ & Adulto & Prostração, dispneia \\
\hline $12^{\text {II }}$ & 2009 & Zoológico & $\begin{array}{l}\text { Arara-vermelha } \\
\text { (Ara chloropterus) }\end{array}$ & Adulto & Encontrado morto \\
\hline $13^{\text {II }}$ & 2009 & Zoológico & Arara-canindé & Adulto & Prostração \\
\hline 14 & 2011 & Domiciliar & $\begin{array}{l}\text { Papagaio-verdadeiro } \\
\text { (Amazona aestiva) }\end{array}$ & 4 meses & Encontrado morto \\
\hline 15 & 2011 & $\begin{array}{l}\text { Centro de } \\
\text { triagem }\end{array}$ & Papagaio-verdadeiro & NI & NI \\
\hline 16 & 2012 & $\begin{array}{l}\text { Criatório } \\
\text { comercial }\end{array}$ & Calopsita & 3 meses & $\begin{array}{c}\text { Anorexia, } \\
\text { emagrecimento, } \\
\text { secreção nasal, diarreia }\end{array}$ \\
\hline
\end{tabular}

${ }^{\mathrm{I}}$ Primeiro surto, ${ }^{\mathrm{II}}$ segundo surto; NI = dado não informado.

dias de idade. Desses animais mortos, seis foram encaminhados para necropsia e apenas um (caso 16) apresentou clamidiose. 0 proprietário, que tinha contato bastante próximo com os animais, estava com quadro de doença respiratória crônica intermitente não responsiva ao tratamento com antibióticos há mais de dois meses.

De acordo com os achados anatomopatológicos e de IHQ 12 aves morreram devido à clamidiose (casos 1, 4, 5, 7 a 14 e 16). As outras quatro apresentavam IHQ positiva para Chlamydia nas células de Kupffer do fígado, no entanto, não se observou lesão compatível com clamidiose. Essas aves morreram devido à: septicemia bacteriana (caso 2), endocardite bacteriana (caso 3) e aspergilose (casos 6 e 15).

As alterações observadas na necropsia dos psitacídeos com clamidiose foram: fígado aumentado $(4 / 12)$ e com áreas branco-amareladas (3/12) (Fig.1), baço aumentado (2/12) e rompido (1/12), saco pericárdico com deposição de fibrina (1/12) e órgãos da cavidade celomática recobertos por fibrina (1/12). Em três casos não havia lesões macroscópicas significativas.

Na avaliação histopatológica as principais lesões encontravam-se no fígado e eram caracterizadas por infiltrado de linfócitos, plasmócitos e macrófagos predominantemente na região portal (10/12) com necrose de coagulação ou fibrinoide multifocal (7/12) (Fig.2A), hiperplasia de ductos biliares (8/12) e acúmulo de hemossiderina no citoplasma de macrófagos na região portal ou próximo às áreas de necrose $(9 / 12)$. No baço observou-se necrose fibrinoide associado a infiltrado de macrófagos e depleção linfoide $(9 / 12)$ com hemossiderose (9/12). Outros achados observados foram: sacos aéreos com infiltrado predominante de ma-

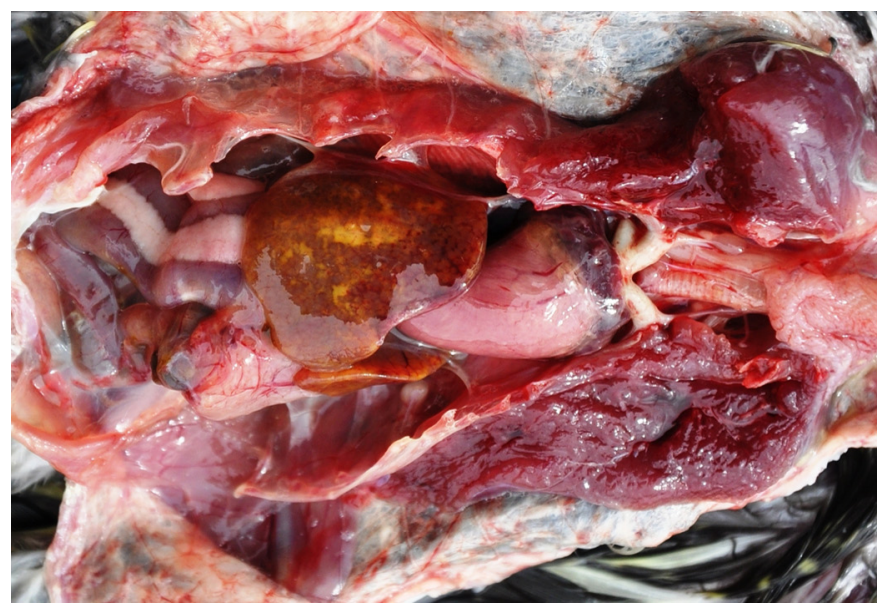

Fig.1. Fígado aumentado de volume e com áreas amareladas, em psitacídeo com clamidiose.

crófagos, linfócitos e plasmócitos (4/12); coração com deposição de fibrina acompanhado de infiltrado predominante de heterófilos no epicárdio (2/12); bursa de Fabricius com rarefação (1/12) ou necrose (1/12) linfoide; rins com necrose fibrinoide multifocal circundada por infiltrado de macrófagos, linfócitos e plasmócitos (1/12) ou múltiplos granulomas compostos por centros de necrose fibrinoide circundada por células gigantes multinucleadas $(1 / 12)$ e nos pulmões deposição de fibrina com infiltrado de macrófagos no lúmen de parabrônquios (1/12). Observaram-se ainda inclusões basofílicas intracitoplasmáticas (corpos elementares) em hepatócitos (2/12) (Fig.2B), e em macrófagos no baço e nos rins (1/12).

Os resultados da IHQ anti-Chlamydia estão apresentados no Quadro 2. Observou-se marcação no citoplasma de macrófagos nas áreas de inflamação e/ou necrose em fígado (15/16) (Fig.2C), baço (7/11) (Fig.2D), pulmões (3/11), rins (2/10), intestinos (2/4), sacos aéreos (1/4) (Fig.2E) e bursa de Fabricius (1/2). Em um caso que a ave apresentava polisserosite e granulomas renais, a marcação foi evidenciada apenas nos rins em citoplasma de macrófagos ou em áreas centrais de necrose dos granulomas (Fig.2F). No entanto, esse foi o único animal enviado congelado para necropsia, os demais eram refrigerados.

\section{DISCUSSÃO}

No presente estudo a clamidiose foi observada em diferentes espécies de psitacídeos e os filhotes foram os mais afetados. A caturrita foi a espécie com maior número de casos positivos. Essa espécie é comumente criada como ave de estimação no estado do Rio Grande do Sul. A maioria dos animais acometidos eram provenientes do tráfico ilegal de animais (apreensão ou centro de triagem), o que demonstra que situações de estresse, deficiência nutricional e imunossupressão são fatores predisponentes para que aves portadoras desenvolvam clamidiose.

Essa enfermidade é a principal zoonose transmitida por psitacídeos e pode causar doença fatal em humanos (Petrovay \& Balla 2008, Proença et al. 2011). A clamidiose é considerada uma importante doença ocupacional e vários estudos apontam sorologia positiva em funcionários 

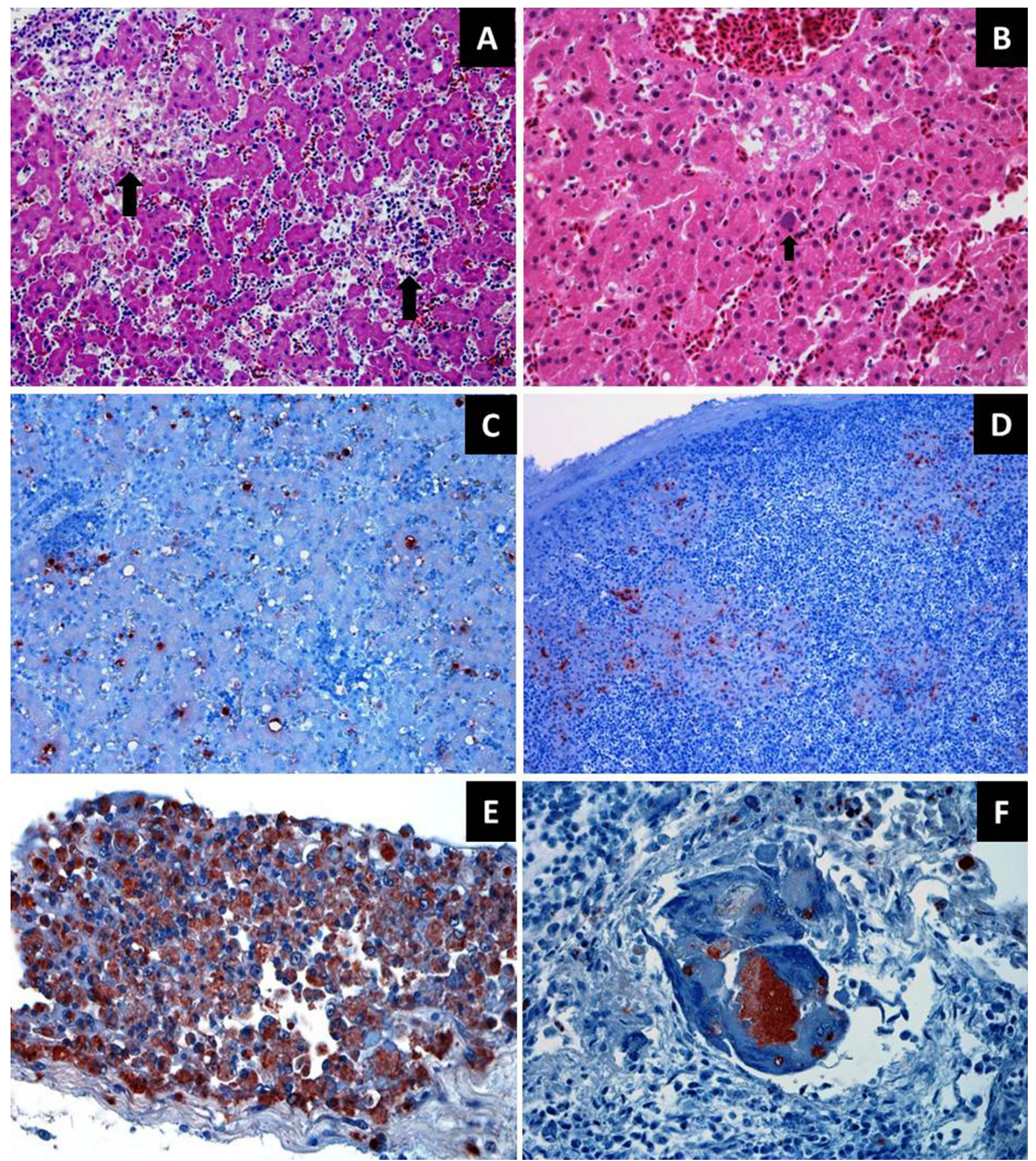

Fig.2. Clamidiose em psitacídeos. (A) Hepatite necrótica mononuclear (setas). HE, obj.20x. (B) Fígado com inclusão basofílica intracitoplasmática (agregados de bactérias individuais) em hepatócito (seta). H\&E, obj.40x. Imuno-histoquímica anti-Chlamydia: marcação positiva em (C) fígado, (D) baço, (E) sacos aéreos e (F) rins. Método estreptavidina-biotina ligada à peroxidase, obj.20x (C e D), obj.40x (E e F).

de zoológicos e criatórios de aves (Heddema et al. 2006, Vanrompay et al. 2007, Harkinezhad et al. 2009, Raso et al. 2010). No surto descrito neste estudo, várias pessoas que entraram em contato com as caturritas, adoecerem. Heddema et al. (2006) descrevem um surto de clamidiose em humanos em um hospital veterinário e Raso et al. (2010) também relatam casos em funcionários de zoológicos.

No Brasil, trabalhos pioneiros demonstraram a infecção por Chlamydia psittaci em psitacídeos por sorologia, imunofluorêscencia direta e reação em cadeia da polime- 
Quadro 2. Distribuição e intensidade da marcação de imuno-histoquímica anti-Chlamydia nos casos de clamidiose em psitacídeos

\begin{tabular}{ccccccccc}
\hline Caso & Fígado & Baço & Pulmões & $\begin{array}{c}\text { Sacos } \\
\text { aéreos }\end{array}$ & Coração & Rins & $\begin{array}{c}\text { Bursa de } \\
\text { Fabricius }\end{array}$ & Intestinos \\
\hline 1 & + & NR & NR & NR & NR & NR & NR & NR \\
$2^{*}$ & + & NR & NR & NR & NR & - & NR & NR \\
$3^{*}$ & ++ & - & NR & NR & NR & - & NR & - \\
4 & + & NR & - & NR & - & - & NR & NR \\
5 & + & - & - & NR & - & - & NR & NR \\
$6^{*}$ & + & - & - & NR & - & NR & NR & NR \\
7 & + & +++ & - & NR & NR & - & NR & NR \\
8 & +++ & +++ & NR & NR & - & NR & +++ & NR \\
9 & + & +++ & - & NR & - & - & NR & NR \\
10 & ++ & + & ++ & NR & - & NR & NR & NR \\
11 & +++ & +++ & +++ & +++ & NR & +++ & NR & +++ \\
12 & +++ & +++ & - & - & NR & - & NR & +++ \\
13 & +++ & +++ & NR & - & NR & NR & NR & - \\
14 & - & - & - & - & - & +++ & NR & NR \\
$15 *$ & + & NR & - & NR & NR & NR & NR & NR \\
16 & ++ & NR & + & NR & - & - & - & NR
\end{tabular}

NR = não realizado; Intensidade de marcação (IHQ): - negativa, + discreta, ++ moderada, +++ acentuada; * Aves apenas com marcação nas células de Kupffer.

rase (PCR) (Raso et al. 2002, 2004, 2006). Na clamidiose, as manifestações clínicas e as lesões macroscópicas podem ser inespecíficas, o que muitas vezes dificulta o diagnóstico (Gerlach 1994, Raso et al. 2004, Ecco et al. 2009). Pela avaliação anatomopatológica observou-se que as lesões mais significativas encontram-se no fígado, como observado em outros trabalhos (Ecco et al. 2009). Segundo Gerlach (1994), em baço, pulmões, coração, sacos aéreos, rins e bursa de Fabricius também podem ser evidenciadas lesões. Dependendo da forma clínica da doença (aguda, subaguda ou crônica) as lesões podem variar. Na forma aguda é comum observar hepatomegalia, peritonite fibrinosa, aerossaculite, pericardite, peri-hepatite, pneumonia, enterite e nefrite. De acordo com Ecco et al. (2006), coração, pulmões e sacos aéreos não são comumente afetados, sendo que no presente trabalho esse resultado também foi observado. Nesse estudo 11/12 aves apresentaram lesões características da forma aguda da doença.

No exame histopatológico, as únicas estruturas específicas das clamídias são os corpos elementares, que muitas vezes não são visualizados. Nesse trabalho, em apenas duas aves observaram-se essas estruturas e, em outros estudos semelhantes, os corpos elementares foram identificados em sete de 13 casos (Elder \& Brown 1999) e em dois de 15 psitacídeos (Ecco et al. 2009). Assim como nesse estudo, a principal lesão histológica da clamidiose é a hepatite histiocitária e linfoplasmocitária, podendo ser associada à necrose multifocal, hiperplasia de ductos biliares e hemossiderose (Abdul-Aziz et al. 2008, Ecco et al. 2009).

Em casos crônicos da doença observa-se granulomas no fígado e pulmões (Gerlach 1994). Em surtos de clamidiose em psitacídeos observaram-se granulomas hepáticos em 5/10 (Raso et al. 2004) e em 6/15 aves (Ecco et al. 2009). No presente estudo, dos 12 casos, apenas um tinha lesões compatíveis com a forma crônica da doença. No entanto, nesse caso os granulomas foram observados apenas nos rins com imunomarcação anti-Chlamydia nos centros necróticos. A visualização das lesões, bem como a imunomarcação em fígado e baço foram prejudicados porque o cadáver dessa ave foi conservado pelo congelamento.

O isolamento e identificação de Chlamydia psittaci são considerados o teste de referência para o diagnóstico de clamidiose, no entanto essa técnica é pouco utilizada. Por ser uma bactéria intracelular obrigatória, necessita um correto armazenamento das amostras e precisa ser cultivada em ovos embrionados ou linhagens celulares, em laboratórios com alto nível de biossegurança, o que dificulta a realização do procedimento na rotina de diagnóstico (Vanrompay et al. 1992, Sachse et al. 2009, Proença et al. 2011). Devido à dificuldade na cultura e isolamento dessa bactéria, a PCR, a imunofluorêscencia direta e os exames sorológicos são as principais técnicas utilizadas no diagnóstico (Vanrompay et al. 1992, Vanrompay et al. 1994, Raso et al. 2002, 2004, 2006, Verminnen et al. 2006). A PCR é o único método de diagnóstico comercial disponível no país (Proença et al. 2011). Esses métodos são rápidos e altamente confiáveis, no entanto não diferenciam as aves portadoras de doentes. A IHQ é considerada a forma de diagnóstico post mortem mais acurada para a clamidiose e é amplamente utilizada como exame de rotina em laboratórios de patologia em países como os Estados Unidos (Elder \& Brown 1999). Os principais órgãos de eleição para o diagnóstico de clamidiose por IHQ são fígado e baço (Elder \& Brown 1999, Ecco et al. 2009), sendo que nesse estudo todas as aves apresentavam marcação no fígado e sete no baço (7/9). Nesse trabalho, quatro aves morreram devido à infecção causada por outros agentes etiológicos e apresentaram marcação na IHQ para Chlamydia em células de Kupffer. Sendo assim, pela IHQ pode-se determinar se a bactéria estava relacionada à lesão (imunomarcação) e causou a morte da ave ou se a imunomarcação ocorreu apenas em macrófagos residuais do fígado determinando o estado de portador.

Apesar de a IHQ ser uma técnica bastante confiável, alguns cuidados devem ser tomados para que não haja resultados falso-negativos. Apenas seis das 14 caturritas do surto de clamidiose apresentaram imunomarcação anti-Chlamydia. Isso pode ter ocorrido, pois como todas as aves apreendidas foram submetidas à eutanásia, independente de apresentarem ou não sinais clínicos da doença em questão, algumas poderiam ser negativas. No entanto, em estudos retrospectivos, falhas no processamento dos tecidos podem ocorrer com maior frequência. $\mathrm{O}$ formaldeído de baixa qualidade e a permanência desses tecidos por longo tempo nesse fixador pode mascarar os epítopos e alterar a habilidade dos anticorpos em reconhecer os antígenos presentes (Webster et al. 2009). Nos casos de clamidiose, a interpretação da marcação também é outro ponto bastante crítico. A utilização de diaminobenzidina (DAB) como cromógeno pode criar problemas na interpretação em casos de lesões hepáticas e esplênicas causadas por $C$. psittaci, pois é difícil diferenciar imunomarcação marrom de pigmento férrico e biliar (Elder \& Brown 1999). Para minimizar esse problema, no presente trabalho utilizou-se o cromógeno 3-amino-9-etilcarbazol (AEC) que tem cor vermelha e pode ser facilmente diferenciado desses pigmentos. 
0 presente estudo permitiu concluir que a clamidiose é uma doença frequente em psitacídeos no Rio Grande do Sul e o histórico clínico e as lesões anatomopatológicas associadas à identificação do agente são fundamentais para o diagnóstico definitivo de clamidiose. A IHQ foi o método de diagnóstico confirmatório utilizado nos casos aqui descritos e poderá ser empregada como método de diagnóstico definitivo post mortem de clamidiose.

Agradecimentos.- À Professora Elisabeth Howerth do Departamento de Patologia, Faculdade de Medicina Veterinária da Universidade da Georgia, Estados Unidos, por nos ceder gentilmente o controle positivo de Chlamydia para realização da IHQ. À Coordenação de Aperfeiçoamento de Pessoal e Nível Superior (CAPES) e Conselho Nacional de Desenvolvimento Científico e Tecnológico (CNPq) pelo apoio financeiro.

\section{REFERÊNCIAS}

Abdul-Aziz T., Fletcher 0. \& Barnes H.J. 2008. Hepatobiliary system, p.202-237. In: Fletcher O.J. (Ed.), Avian Histopathology. Omni Press, Madison.

Andersen A.A. \& Vanrompay D. 2008. Avian Chlamydiosis (psittacosis, ornithosis), p.971-986. In: Saif Y.M. (Ed.), Diseases of Poultry. $12^{\text {th }}$ ed. Blackwell, Iowa.

Ecco R., Preis I.S., Martins N.R.S., Vilela D.A.R. \& Shivaprasad H.L. 2009. An outbreak of chlamydiosis in captive psittacines. Braz. J. Vet. Pathol. 2(2):85-90.

Elder J. \& Brown C. 1999. Review of techniques for the diagnosis of Chlamydia psittaci infection in psittacine birds. J. Vet. Diagn. Invest. 11:539541.

Gerlach H. 1994. Chlamydia, p.984-996. In: Richie B.W., Harrison G.J. \& Harrison L.R. (Eds), Avian Medicine: principles and application. Wingers, Florida.

Harkinezhad T., Verminnen K., De Buyzere M., Rietzschel E., Bekaert S. \& Vanrompay D. 2009. Prevalence of Chlamydophila psittaci infections in a human population in contact with domestic and companion birds. J. Med. Microbiol. 58:1207-1212.

Heddema E.R., Van Hannen E.J., Duim B., De Jongh B.M., Kaan J.A., Van Kessel R., Lumeij J.T., Visser C.E. \& Vandenbroucke-Grauls C.M.J.E. 2006. An outbreak of psittacosis due to Chlamydophila psittaci genotype A in a veterinary teaching hospital. J. Med. Microbiol. 55:1571-1575.

Kaleta E.F. \& Taday M.A. 2003. Avian host range of Chlamydophila spp. based on isolation, antigen detection and serology. Avian Pathol. $32: 435-462$
Longbottom D. \& Coulter L.J. 2003. Animal chlamydiosis and zoonotic implications. J. Comp. Pathol. 128:217-244.

Petrovay F. \& Balla E. 2008. Two fatal cases of psittacosis caused by Chlamydophila psittaci. J. Med. Microbiol. 57:1296-1298.

Proença L.M., Fagliari J.J. \& Raso T.F. 2011. Infecção por C. psittaci: uma revisão com ênfase em psitacídeos. Ciência Rural 41:841-847.

Raso T.F., Berchieri Jr A. \& Pinto A.A. 2002. Evidence of Chlamydophila psittaci infection in captive amazon parrots in Brazil. J. Zoo Wildl. Med. 32:118-121.

Raso T.F., Godoy S.N., Milanelo L., De Souza C.A.I., Matuschima E.R., Araújo J.P. \& Pinto A.A. 2004. An outbreak of chlamydiosis in captive bluefronted Amazon parrots (Amazona aestiva) in Brazil. J. Zoo Wildl. Med. 35:94-96.

Raso T.F., Seixas G.H.F., Guedes N.M.R. \& Pinto A.A. 2006. Chlamydophila psittaci in free-living Blue-fronted Amazon parrots (Amazona aestiva) and Hyacinth macaws (Anodorhynchus hyacinthinus) in the Pantanal of Mato Grosso do Sul, Brazil. Vet. Microbiol. 117:235-241.

Raso T.F., Carrasco A.O.T., Silva J.C.R., Marvulo M.F.V. \& Pinto A.A. 2010. Seroprevalence of antibodies to Chlamydophila psittaci in zoo workers in Brazil. Zoonoses Public Helth 57:411-416.

Sachse K., Vretou E., Livingstone M., Borel N., Pospischil A. \& Longbottom D. 2009. Recent developments in the laboratory diagnosis of chlamydial infections. Vet. Microbiol. 135:2-21.

Van Loock M., Loots K., Van Heerden M., Vanrompay D. \& Goddeeris B.M. 2006. Exacerbation of Chlamydophila psittaci pathogenicity in turkeys superinfected by Escherichia coli. Vet. Res. 37:745-755.

Vanrompay D., Ducatelle R. \& Haesebrouck F. 1992. Diagnosis of avian chlamydiosis: specificity of the modified Gimenez staining on smears and comparison of the sensitivity of isolation in eggs and three different cell cultures. Zentralbl. Veterinärmed B 39:105-112.

Vanrompay D., Van Neron A., Ducatelle R. \& Haesebrouck F. 1994. Evaluation of five immunoassays for detection of Chlamydia psittaci in cloacal and conjunctival specimens from turkeys. J. Clin. Microbiol. 32:1470-1474.

Vanrompay D., Harkinezhad T., Van de Walle M., Beeckman D., Van Droogenbroeck C., Verminnen K., Leten R., Martel A. \& Cauwerts K. 2007. Chlamydophila psittaci transmission from pet birds to humans. Emerg. Infect. Dis. 13(7):1108-1110.

Verminnen K., Van Loock M., Hafez H.M., Ducatelle R., Haesebrouck F. \& Vanrompay D. 2006. Evaluation of a recombinant enzyme-linked immunosorbent assay for detecting Chlamydophila psittaci antibodies in turkey sera. Vet. Res. 37:623-632.

Webster J.D., Miller M.A., DuSold D. \& Ramos-Vara J. 2009. Effects of prolonged formalin fixation on diagnostic immunohistochemistry in domestic animals. J. Histochem. Cytochem. 57(8):753-761. 